\title{
Article
}

\section{Metal-Organic Framework MIL-101(Fe) Nanoparticles Decorated with Ag Nanoparticles for Regulating the Photocatalytic Phenol Oxidation Pathway for $\operatorname{Cr}(V I)$ Reduction}

Gong, Jianqiu, Zhang, Weiwei, Sen, Tapas, Yu, Yichen, Liu, Yuchen, Zhang, Jinlong and Wang, Lingzhi

Available at https://clok.uclan.ac.uk/37582/

Gong, Jianqiu, Zhang, Weiwei, Sen, Tapas orcid iconORCID: 0000-0002-04637485, Yu, Yichen, Liu, Yuchen, Zhang, Jinlong and Wang, Lingzhi (2021) MetalOrganic Framework MIL-101(Fe) Nanoparticles Decorated with Ag Nanoparticles for Regulating the Photocatalytic Phenol Oxidation Pathway for Cr(VI) Reduction. ACS Applied Nano Materials, 4 (5). pp. 4513-4521.

It is advisable to refer to the publisher's version if you intend to cite from the work. http://dx.doi.org/10.1021/acsanm.1c00119

For more information about UCLan's research in this area go to http://www.uclan.ac.uk/researchgroups/ and search for <name of research Group>.

For information about Research generally at UCLan please go to http://www.uclan.ac.uk/research/

All outputs in CLoK are protected by Intellectual Property Rights law, including Copyright law. Copyright, IPR and Moral Rights for the works on this site are retained by the individual authors and/or other copyright owners. Terms and conditions for use of this material are defined in the policies page. 
Metal-Organic Framework MIL-101(Fe) Nanoparticles Decorated with Ag Nanoparticles for Regulating the Photocatalytic Phenol Oxidation Pathway for Cr(VI) Reduction

Jianqiu Gong ${ }^{\dagger}$, Weiwei Zhang ${ }^{\dagger}$, Tapas Sen ${ }^{*}$, Yichen Yu, Yuchen Liu, Jinlong Zhang ${ }^{\dagger}$, Lingzhi Wang ${ }^{\dagger} *$

† Shanghai Engineering Research Center for Multi-media Environmental Catalysis and Resource Utilization, Key Lab for Advanced

Materials and Joint International Research Laboratory of Precision Chemistry and Molecular Engineering, Feringa Nobel Prize Scientist Joint Research Center, Institute of Fine Chemicals, School of Chemistry and Molecular Engineering, East China University of Science \& Technology, 130 Meilong Road, Shanghai, 200237, China.

\School of Physical Sciences \& Computing, Centre of Materials Sciences, University Of Central Lancashire, Preston, UK. 


\section{ABSTRACT}

Photocatalysis is a promising technology to treat dilute phenol-Cr(VI) mixture, where photo-induced electrons are commonly thought of as the main active species for $\mathrm{Cr}(\mathrm{VI})$ reduction. However, it generally depends on the surface adsorption to achieve efficient electron transfer. Meanwhile, the possible contribution of reductive quinone derivatives oxidized from phenol to $\mathrm{Cr}(\mathrm{VI})$ reduction has been rarely explored. The key is to explicitly understand the relation between the phenol oxidation pathway and $\mathrm{Cr}(\mathrm{VI})$ reduction. Herein, $\mathrm{Ag} / \mathrm{AgCl} / \mathrm{MIL}-101(\mathrm{Fe})$ prepared by directly loading $\mathrm{Ag}$ nanoparticles on MIL-101(Fe) was applied to the joint treatment of phenol and $\mathrm{Cr}(\mathrm{VI})$. The role of quinone derivatives in reducing $\mathrm{Cr}(\mathrm{VI})$ was revealed by excluding the surface adsorption. During the phenol oxidation, $\cdot \mathrm{OH}$ radicals were more consumed in the initial stage for the ring-opening of phenol. Meanwhile, ${ }^{1} \mathrm{O}_{2}$ evolved from $\cdot \mathrm{O}_{2}{ }^{-}$ gradually caused the accumulation of reductive quinone intermediates, which dramatically accelerated the $\mathrm{Cr}(\mathrm{VI})$ reduction afterwards. This study demonstrates the significance of controlling the evolution process of active oxygen species for the joint photocatalytic treatment of phenol-Cr(VI) mixture.

Keywords: Photocatalysis; $\mathrm{Ag} / \mathrm{AgCl} / \mathrm{MIL}-101(\mathrm{Fe}) ; \mathrm{Cr}(\mathrm{VI})$ reduction; phenol degradation; quinone derivatives; ${ }^{1} \mathrm{O}_{2}$ 


\section{INTRODUCTION}

Phenol and Cr(VI) are the commonly coexistent pollutants discharged from the leather tanning and wood products industries. ${ }^{1-5}$ Reactions between them can reduce $\mathrm{Cr}(\mathrm{VI})$ to less toxic $\mathrm{Cr}(\mathrm{III})$ but generally occurs under strongly acid conditions with high concentrations. ${ }^{6,7}$ Photocatalysis has been commonly used to reduce $\mathrm{Cr}(\mathrm{VI})$ and degrade phenol with comparatively lower concentrations; $;{ }^{8-12}$ photo-induced electrons are thought as the main active species for $\mathrm{Cr}(\mathrm{VI})$ reduction. ${ }^{13-16}$ Therefore, photocatalysts with high activity generally have enhanced hole-electron separation efficiency. ${ }^{17-22}$ This case is not vice versa since the electron-induced $\mathrm{Cr}(\mathrm{VI})$ reduction requires efficient surface adsorption of anion $\mathrm{Cr}(\mathrm{VI})$ on the photocatalyst, which restricts the photocatalysts with low isoelectric points to strongly acid conditions. ${ }^{23-26}$

Meanwhile, the quinone derivatives oxidized from phenol, including hydroquinone (HQ) and semiquinone (SQ), are effective for $\mathrm{Cr}(\mathrm{VI})$ reduction. It is highly possible that these intermediates could also contribute to the $\mathrm{Cr}(\mathrm{VI})$ reduction during photocatalysis, which is however, hard to determine since the concentration may be dynamically varied with the reaction phase. For example, quinone derivatives can be formed in the presence of different active oxygen species including $\cdot \mathrm{OH},{ }^{27,}{ }^{28} \cdot \mathrm{O}_{2}{ }^{-29,}, 30$ and ${ }^{1} \mathrm{O}_{2},{ }^{31-33}$ but may undergo fast ring-opening reaction when further attacked by aggressive $\cdot \mathrm{OH}$ radicals. ${ }^{34-37} \mathrm{On}$ the other hand, the active oxygen species of $\cdot \mathrm{OH}, \cdot \mathrm{O}_{2}{ }^{-}$ and ${ }^{1} \mathrm{O}_{2}$ in the photocatalytic system can mutually transform to each other under certain conditions, ${ }^{38,39}$ which further complicates the situation about exploring the reduction effect of quinone derivatives. An explicit understanding of the role of quinone derivatives in reducing $\mathrm{Cr}(\mathrm{VI})$ is necessary to help us extrapolate to the complex systems of waste phenol-Cr(VI) mixtures, which requires the fine unraveling of the formation-evolution of active oxygen species.

MOFs with high specific surface area and highly tunable structure characteristics have shown promising potential in photocatalytic water decontamination. ${ }^{40-44}$ The abundant structure characteristics of MOFs provide diversified options for the tuning of interfacial interaction. ${ }^{45-48}$ Herein, $\mathrm{Ag} / \mathrm{AgCl} / \mathrm{MIL}-101(\mathrm{Fe})$ was fabricated by simply 
loading Ag nanoparticles on MIL-101(Fe) and applied to the photocatalytic treatment of phenol-Cr(VI). It showed a cooperation effect for the phenol degradation and $\mathrm{Cr}(\mathrm{VI})$ reduction with excellent cyclic stability under weak acid to near-neutral conditions. The evolution of active oxygen species including $\cdot \mathrm{OH}$ and ${ }^{1} \mathrm{O}_{2}$ under visible light irradiation and their relation with the phenol oxidation and $\mathrm{Cr}(\mathrm{VI})$ reduction were explicitly explored. The former caused the fast ring-opening of phenol in the initial phase, and the latter caused the gradual accumulation of quinone derivatives. The contribution of quinone derivatives to $\mathrm{Cr}(\mathrm{VI})$ reduction was identified besides the photo-induced electrons. This study provides a new way for photocatalytic $\mathrm{Cr}(\mathrm{VI})$ reduction in mixed phenol-Cr(VI) system by regulating the photocatalytic oxidation pathway of phenol.

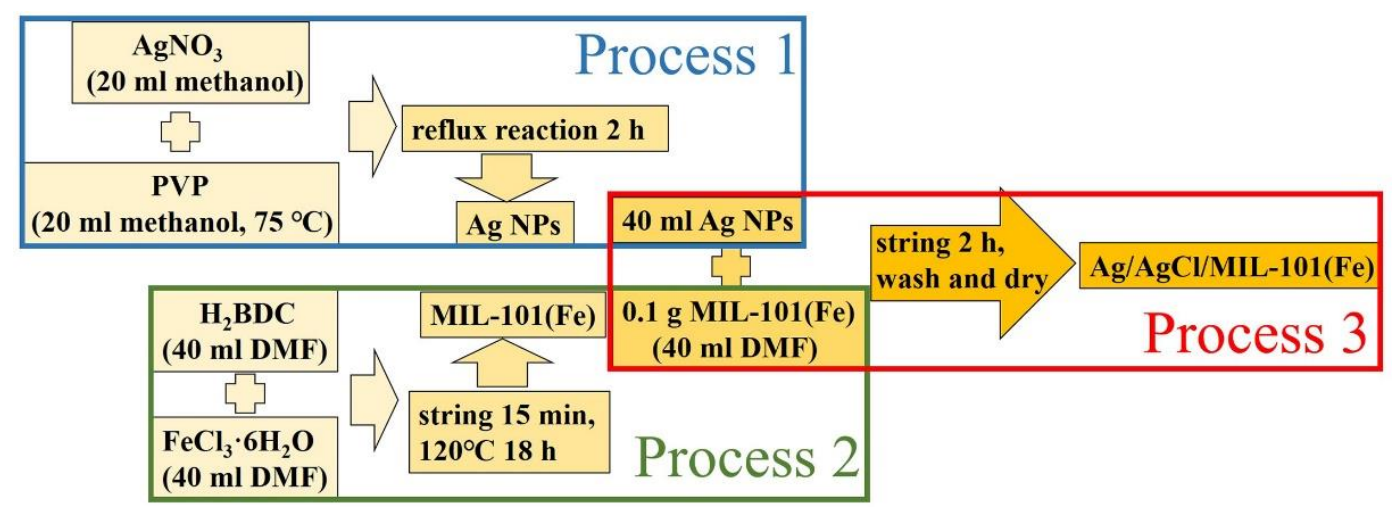

Scheme 1. Synthesis of Ag/AgCl/MIL-101.

\section{EXPERIMENTAL SECTION}

2.1. Chemicals and Materials. $\mathrm{N}, \mathrm{N}$-dimethyl formamide (DMF, 99.8wt\%), 1,4benzenedicarboxylate $\left(\mathrm{H}_{2} \mathrm{BDC}, 99 \mathrm{wt} \%\right)$, silver nitrate $\left(\mathrm{AgNO}_{3}, 99.8 \mathrm{wt} \%\right)$ and methanol were purchased from Aladdin industrial corporation (Shanghai, China). Anhydrous ethanol, potassium dichromate, iron(III) chloride hexahydrate $\left(\mathrm{FeCl}_{3} \cdot 6 \mathrm{H}_{2} \mathrm{O}\right.$, 99wt\%) and polyvinylpyrrolidone (PVP, K-30) were purchased from Sinopharm Chemical Reagent Co., Ltd., China. All the chemicals were used without further purification.

2.2. Synthesis of Ag nanoparticles. In the synthesis process of Ag nanoparticles (NPs), 
$85 \mathrm{mg} \mathrm{AgNO}_{3}$ and $60 \mathrm{mg}$ PVP were used to prepare $\mathrm{Ag}$ NPs for $0.5 \% \mathrm{Ag} / \mathrm{AgCl} / \mathrm{MIL}-$ 101(Fe), $170 \mathrm{mg} \mathrm{AgNO}_{3}$ and $120 \mathrm{mg}$ PVP were used to prepare Ag NPs for $1 \%$ $\mathrm{Ag} / \mathrm{AgCl} / \mathrm{MIL}-101(\mathrm{Fe})$, and $340 \mathrm{mg} \mathrm{AgNO}_{3}$ and $180 \mathrm{mg}$ PVP were used to prepare $\mathrm{Ag}$ NPs for $2 \% \mathrm{Ag} / \mathrm{AgCl} / \mathrm{MIL}-101(\mathrm{Fe})$. In a typical procedure, $\mathrm{AgNO}_{3}$ and PVP were added to two beakers with $20 \mathrm{~mL}$ methanol, respectively. The $\mathrm{AgNO}_{3}$ solution was then added into the PVP solution drop by drop. Finally, the mixture was heated to $75^{\circ} \mathrm{C}$ under magnetic stirring and maintained for $2 \mathrm{~h}$ (Scheme 1, Process 1). When the reaction was complete, the solution was cooled to room temperature and used for the next step.

2.3. Synthesis of MIL-101(Fe). The MIL-101(Fe) was fabricated using a simple solvothermal method reported previously. ${ }^{49}$ In a typical procedure, $0.766 \mathrm{~g} \mathrm{H}_{2} \mathrm{BDC}$ and $1.246 \mathrm{~g} \mathrm{FeCl}_{3} \cdot 6 \mathrm{H}_{2} \mathrm{O}$ were added to $40 \mathrm{ml}$ DMF respectively. After stirring $15 \mathrm{~min}$, the mixture was transferred to a Teflon-lined stainless steel autoclave and placed in an oven at $120{ }^{\circ} \mathrm{C}$ for $18 \mathrm{~h}$ (Scheme 1, Process 2). The obtained products were washed with DMF, deionized water and ethanol, and dried prior to use.

2.4. Synthesis of $\mathbf{A g} / \mathbf{A g C l} / \mathbf{M I L}-101(\mathbf{F e}) .40 \mathrm{~mL}$ as-synthesized Ag NPs solution was added drop by drop into $40 \mathrm{~mL}$ DMF of MIL-101(Fe) $(0.1 \mathrm{~g})$ under vigorous stirring, and then the mixed solution was further stirred at room temperature for $2 \mathrm{~h}$. Subsequently, the sample was centrifuged at $10000 \mathrm{rpm}$ for 5 minutes, washed with numerous ethanol and ultrapure water, and dried at $60{ }^{\circ} \mathrm{C}$ in a vacuum oven (Scheme 1, Process 3). The dark yellow solid powder obtained is $\mathrm{Ag} / \mathrm{AgCl} / \mathrm{MIL}-101(\mathrm{Fe}) . \mathrm{Ag} / \mathrm{AgCl}$ was prepared from $\mathrm{FeCl}_{3}$ and $\mathrm{Ag} \mathrm{NPs}$, and used as the control sample.

2.5. Photocatalytic Tests. The Cr(VI) reduction and the phenol degradation were tested under visible-light irradiation by using a xenon lamp equipped with a light filter $(\geq 420$ $\mathrm{nm}, 300 \mathrm{~W})$. In a typical experiment, $50 \mathrm{mg} \mathrm{Ag} / \mathrm{AgCl} / \mathrm{MIL}-101(\mathrm{Fe})$ was suspended in $50 \mathrm{~mL}$ of $10 \mathrm{mg} / \mathrm{L} \mathrm{Cr}(\mathrm{VI})$ and phenol solution. The $\mathrm{pH}$ was tuned to 6 to prevent the formation of precipitation. ${ }^{50}$ The mixture was stirred for $30 \mathrm{~min}$ without light to reach 
the adsorption-desorption equilibrium. During visible-light irradiation, a certain amount of liquid was taken out to analyze every 15 minutes. The concentration of $\mathrm{Cr}(\mathrm{VI})$ was determined by the diphenylcarbazide (DPC) method. The concentration of phenol was measured by a high-performance liquid chromatography (HPLC) system.

2.6 Characterization. Transmission electron microscopy (TEM) was conducted on a JEOL JEM-2100EX electron microscope, operated at an accelerating voltage of $200 \mathrm{kV}$. X-ray diffraction (XRD) measurements were performed with a Rigaku Ultima IV $(\mathrm{Cu}$ Ka radiation, $\lambda=1.5406 \AA$ ) in the range of $5-80^{\circ}(2 \theta)$. The instrument employed for Xray photoelectron spectrum (XPS) measurements was a PerkinElmer PHI 5000C ESCA system with $\mathrm{Al} \mathrm{K} \alpha$ radiation operated at $250 \mathrm{~W}$. The UV-vis absorption spectroscopy was measured with a Shimadzu UV-2450 spectrometer. Phenol values were monitored using a SHIMADZU SPD-M20A reverse-phase high-performance liquid chromatography (HPLC) system at a flow rate of $1 \mathrm{~mL} \cdot \mathrm{min}^{-1}$ with a RX-C18 column $(4.6 \times 250 \mathrm{~mm}, 5 \mu \mathrm{m})$. The detection of radicals was carried out on a 100G18KG/EMX-8/2.7 Electro-Spin Resonance spectrometer.

\section{RESULTS AND DISCUSSION}
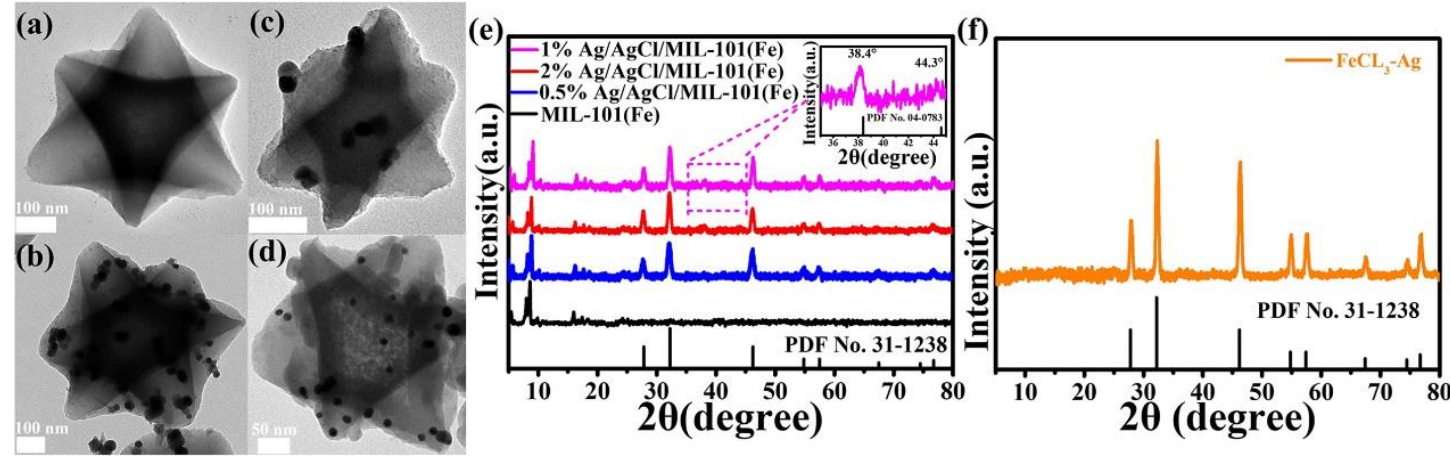

Figure 1. (a-d) TEM images of MIL-101(Fe), $0.5 \% \mathrm{Ag} / \mathrm{AgCl} / \mathrm{MIL}-101(\mathrm{Fe}), 1 \% \mathrm{Ag} / \mathrm{AgCl} / \mathrm{MIL}-$ $101(\mathrm{Fe})$ and $2 \% \mathrm{Ag} / \mathrm{AgCl} / \mathrm{MIL}-101(\mathrm{Fe})$; (e) XRD patterns of different samples; (f) XRD pattern of $\mathrm{Ag} / \mathrm{AgCl}$.

3.1. Structure Characterization. $\mathrm{Ag} / \mathrm{AgCl} / \mathrm{MIL}-101(\mathrm{Fe})$ heterojunction was fabricated via the reaction between $\mathrm{Ag}$ NPs and the $\mathrm{Fe}(\mathrm{III})-\mathrm{Cl}$ in the framework of MIL101(Fe). As shown in Figure 1a, the TEM images of MIL-101(Fe) show an approximately hexagonal shape with an edge length of ca. $550 \mathrm{~nm}$. After the loading of 
Ag nanoparticles, the hexagonal shape becomes less ordered with coarsened and blurred edges, indicating the possible reaction between Ag and MIL-101(Fe) (Figure 1b-d, S1). The NPs have an average size of ca. $20 \mathrm{~nm}$ and become more agglomerate at higher loading content. According to the high-resolution TEM (HRTEM) image of sample $1 \% \mathrm{Ag} / \mathrm{AgCl} / \mathrm{MIL}-101(\mathrm{Fe})$, the loaded NPs have lattice fringes of $\mathrm{d}=0.201 \mathrm{~nm}$ and $\mathrm{d}=0.277 \mathrm{~nm}$ (Figure S2), corresponding to the $\mathrm{Ag}\left(\begin{array}{lll}2 & 0 & 0\end{array}\right)$ and $\mathrm{AgCl}\left(\begin{array}{lll}2 & 0 & 0\end{array}\right)$ planes, respectively. These results demonstrate the formation of $\mathrm{Ag} / \mathrm{AgCl}$ composites on MIL101(Fe).

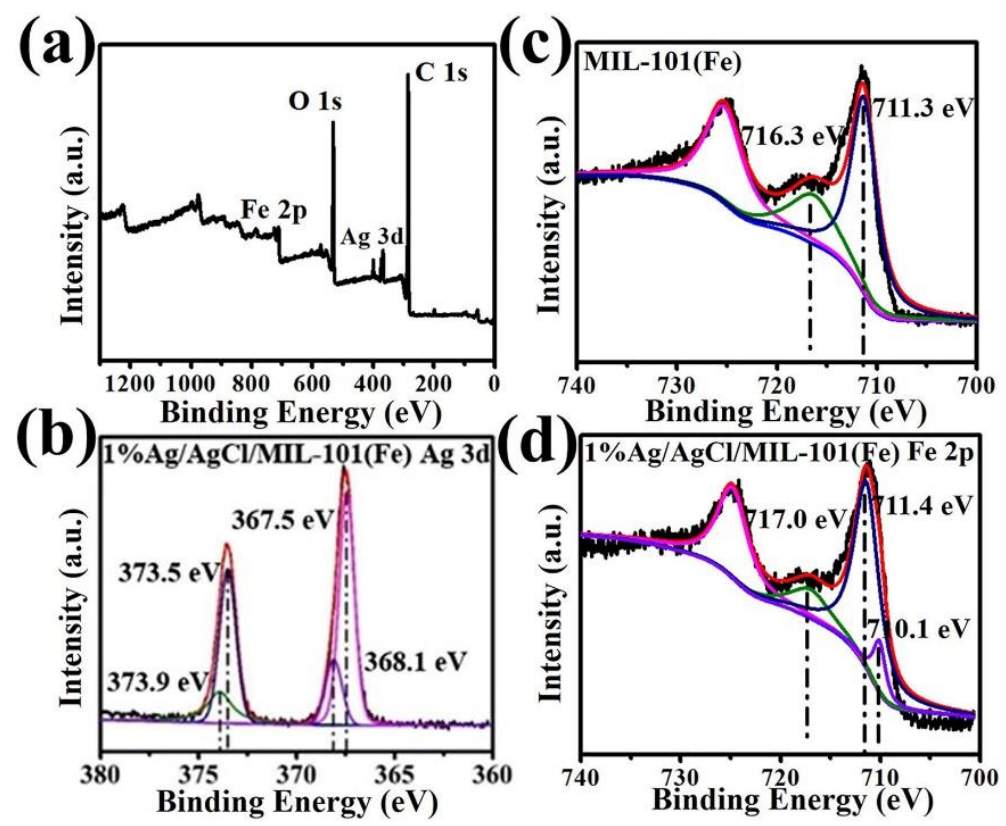

Figure 2. (a) XPS survey spectrum of $1 \% \mathrm{Ag} / \mathrm{AgCl} / \mathrm{MIL}-101(\mathrm{Fe})$; (b) $\mathrm{Ag} 3 \mathrm{~d}$ spectra of $1 \%$ $\mathrm{Ag} / \mathrm{AgCl} / \mathrm{MIL}-101(\mathrm{Fe})$; Fe2p spectra of (c) MIL-101 and (d) 1\% Ag/AgCl/MIL-101.

The XRD measurement was performed to characterize the crystal structures of samples loaded with different amounts of Ag. The obvious peaks at $27.7^{\circ}, 32.4^{\circ}, 46.3^{\circ}$,

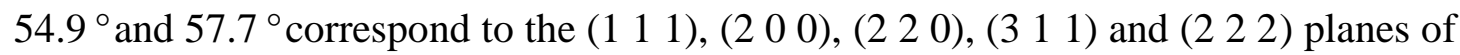
$\mathrm{AgCl}$ (Figure 1f, JCPDS No. 31-1238). The amplified signal at $38.4^{\circ}$ is assigned to the (1 11 1) crystal plane of Ag (JCPDS No. 04-0783). No other obvious characteristic peaks of Ag NPs can be observed (Figure 1e, f), which may be attributed to the small size or small amounts of $\mathrm{Ag}$, suggesting most of $\mathrm{Ag}$ should be oxidized to $\mathrm{AgCl}$. The above results further confirm that the $\mathrm{Ag} / \mathrm{AgCl} / \mathrm{MIL}-101(\mathrm{Fe})$ ternary composite should be formed by simply loading $\mathrm{Ag}$ on MIL-101(Fe). The loading of $\mathrm{Ag} / \mathrm{AgCl}$ is further 
verified by the significantly decreased specific surface area and pore size of MIL-101 (Figure S3). The XPS survey spectrum confirms Ag, Fe and $\mathrm{Cl}$ species in the composite (Figure 2a). The small peaks at 367.5 and $373.9 \mathrm{eV}$ are attributed to metallic Ag (Figure 2b). The MIL-101(Fe) only shows the peaks of Fe (III) at $711.3 \mathrm{eV}$ (Figure 2c). After the loading of Ag, the signal of Fe (II) (Figure 2d) appears as characterized by the peak at $710.1 \mathrm{eV}$ (ca. 9.0\%), which should be attributed to the reaction shown in Eq. 1 .

$$
\mathrm{MIL}-101(\mathrm{Fe}(\mathrm{III}))+\mathrm{Ag}^{0} \rightarrow \mathrm{Ag} / \mathrm{AgCl} / \mathrm{MIL}-101(\mathrm{Fe}(\mathrm{II}, \mathrm{III}))
$$

The UV-Vis absorption spectra of MIL-101(Fe) and $\mathrm{Ag} / \mathrm{AgCl} / \mathrm{MIL}-101(\mathrm{Fe})$ composites are shown in Figure S4. The absorption band around $230 \mathrm{~nm}$ is attributed to the charge transfer from $\mathrm{O}$ to $\mathrm{Fe}$ in the octahedral coordination environment. ${ }^{51}$ The absorption from $320 \mathrm{~nm}$ to the visible region is derived from the charge transfer from the ligand to the $\mathrm{Fe}-\mathrm{O}$ cluster (LMCT) ${ }^{52} \mathrm{AgCl}$ has a strong light absorption in the UV region and the absorption in the visible region is attributed to the surface plasmon resonance (SPR) effect of noble Ag.
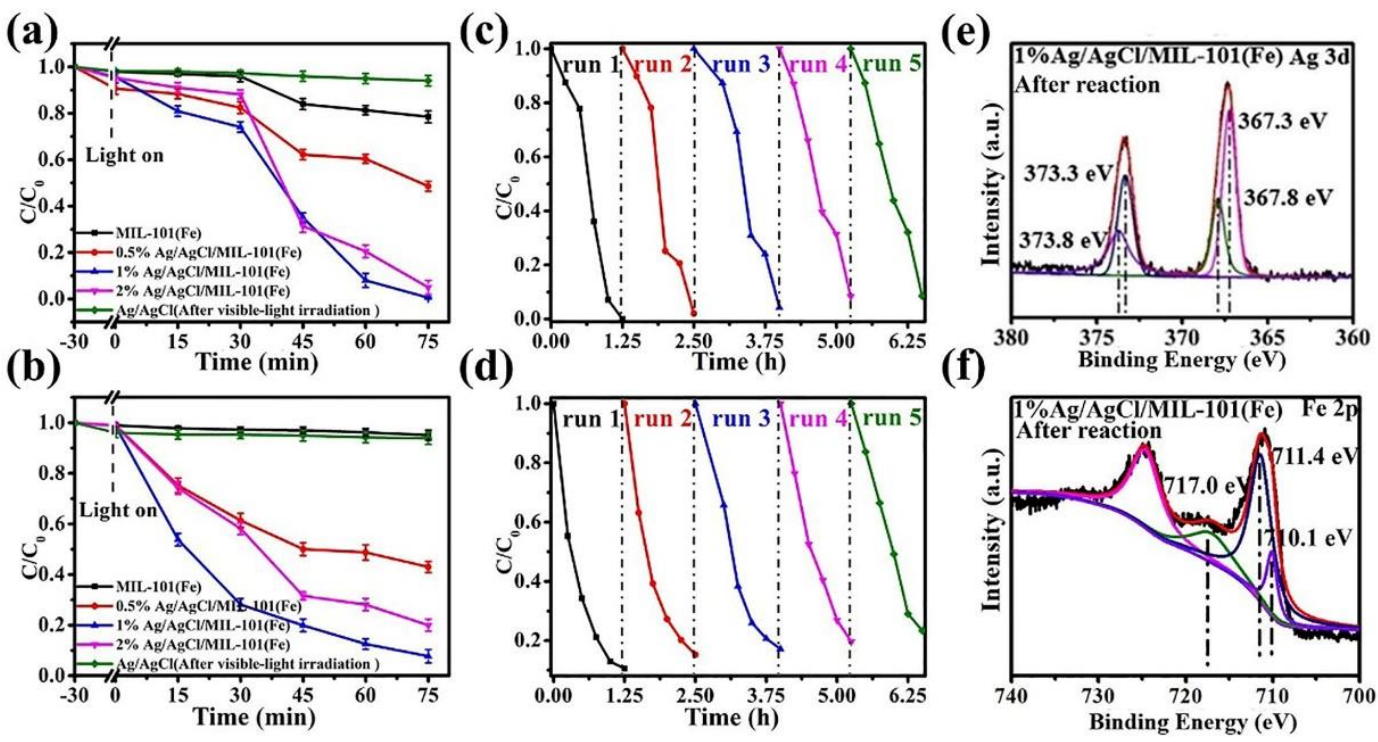

Figure 3. (a) $\mathrm{Cr}(\mathrm{VI})$ reduction and (b) phenol degradation via different samples in the phenol$\mathrm{Cr}(\mathrm{VI})$ mixture; cyclic test for (c) $\mathrm{Cr}(\mathrm{VI})$ reduction and (d) phenol degradation in the phenol$\mathrm{Cr}(\mathrm{VI})$ mixture; (e) Ag3d and (f) Fe2p XPS spectra of 1\% Ag/AgCl/MIL-101(Fe) after reaction.

3.2. Photocatalytic test. The photocatalytic test was carried out in a mixed solution containing $10 \mathrm{mg} / \mathrm{L}$ of $\mathrm{Cr}(\mathrm{VI})$ and $10 \mathrm{mg} / \mathrm{L}$ of phenol under the irradiation of a $300 \mathrm{~W}$ xenon lamp equipped with a $420 \mathrm{~nm}$ filter. The photocatalytic reduction efficiency of 
$\mathrm{Cr}(\mathrm{VI})$ first increases with the increasing amount of $\mathrm{Ag}$ and reaches almost $100 \%$ on sample $1 \% \mathrm{Ag} / \mathrm{AgCl} / \mathrm{MIL}-101(\mathrm{Fe})$ (Figure 3a, S5). It is noted that the $\mathrm{Cr}(\mathrm{VI})$ reduction is obviously accelerated after irradiation for $30 \mathrm{~min}$. Meanwhile, either $\mathrm{Ag} / \mathrm{AgCl}$ or MIL-101(Fe) with the amount equivalent to the counterparts in the $\mathrm{Ag} / \mathrm{AgCl} / \mathrm{MIL}-$ 101(Fe) composite shows negligible activity for $\mathrm{Cr}(\mathrm{VI})$ reduction, implying the activity should be attributed to the cooperative effect between $\mathrm{Ag} / \mathrm{AgCl}$ and MIL-101(Fe). For the phenol degradation, sample $1 \% \mathrm{Ag} / \mathrm{AgCl} / \mathrm{MIL}-101(\mathrm{Fe})$ also shows the best activity (Figure 3b), where ca. $70 \%$ of phenol can be degraded within the first $30 \mathrm{~min}$. From the linear portion of this plot, the apparent quantum efficiency of phenol is $0.31 \%$ (Supplementary Text S1). In comparison, the loading of other noble metals including $\mathrm{Au}$ and $\mathrm{Pt}$ results in less efficient phenol degradation and $\mathrm{Cr}(\mathrm{VI})$ reduction (Table S1). To understand the photocatalytic process, the $\mathrm{Cr}(\mathrm{VI})$ reduction and phenol degradation were also carried out in the single systems (Figure S6a). The $\mathrm{Cr}(\mathrm{VI})$ reduction is significantly retarded in the absence of phenol (Figure S6b). In comparison, the degradation efficiency of phenol is less decreased (Figure S6c). Specifically, compared with the single-pollutant system, the $\mathrm{Cr}(\mathrm{VI})$ reduction and phenol oxidation are increased by $82 \%$ and $24 \%$ in the mixed system, respectively. The above results demonstrate the cooperative effect between $\mathrm{Cr}(\mathrm{VI})$ reduction and phenol oxidation, and the $\mathrm{Cr}(\mathrm{VI})$ reduction is more efficiently promoted in the mixed system.

In order to evaluate the stability of the composites, cyclic experiments were performed over $1 \% \mathrm{Ag} / \mathrm{AgCl} / \mathrm{MIL}-101(\mathrm{Fe})$. The activity can be well preserved after five cyclic experiments (Figure 3c, d). A slightly decreased activity should be due to the unavoidable sample loss during recycling. It is noted from the XPS spectrum that the peaks of metallic Ag increase after the reaction (Figure 3e), accompanied by the improved content of the Fe(II) (ca. 18.2\%, Figure 3f), which, however, keeps almost unvaried from the second run (Figure S7). This result demonstrates the chemical valences of $\mathrm{Fe}$ and $\mathrm{Ag}$ species changed during the first run but soon reached equilibrium. However, the improved $\mathrm{Ag}$ content seems contradictory to the appearance of more $\mathrm{Fe}(\mathrm{II})$ since the formation of $\mathrm{Ag}$ is supposed to be attributed to the electrons transferred from 
MIL-101(Fe), and the remained hole in MIL-101(Fe) is expected to form Fe(III). The specific reason for the valence variation in the first run will be discussed later. Meanwhile, negligible content variation is observed through the XPS survey spectra after the first-run reaction, which excludes the possibility and influence of the particle leaching (Figure S8). The leaching-resistance of the Ag from the composite should be attributed to the chemical anchoring of $\mathrm{Ag} / \mathrm{AgCl}$ on $\mathrm{MIL}-101(\mathrm{Fe})$ through the $\mathrm{Ag}-\mathrm{Cl}-$ Fe bond, which should also be beneficial to the interfacial carrier transfer. The highest and photocurrent and minimum impedance observed from $1 \% \mathrm{Ag} / \mathrm{AgCl} / \mathrm{MIL}-101(\mathrm{Fe})$ verify the promoted charge transfer between different components through the Ag-ClFe bond (Figure S9).
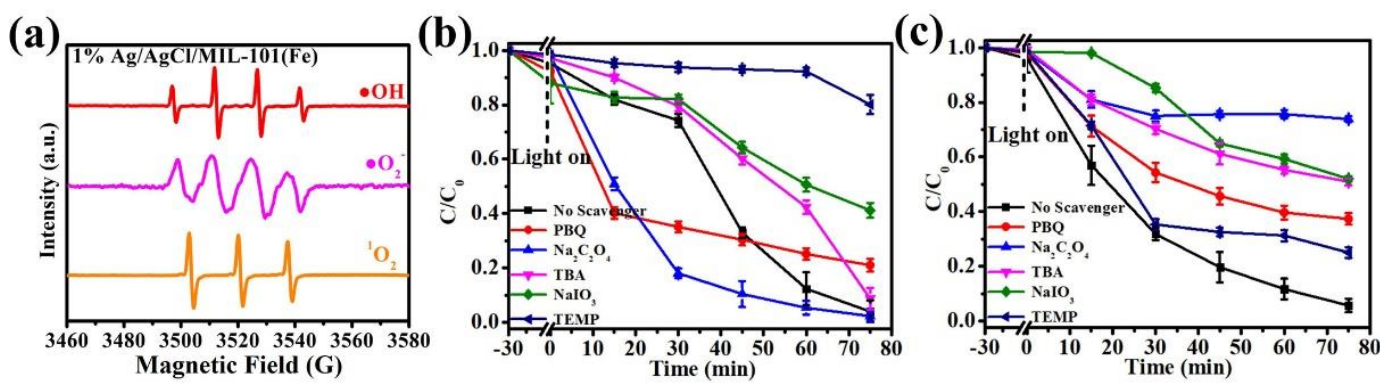

Figure 4. (a) EPR spectra for the detection of $\cdot \mathrm{OH}$ (water, DMPO); $\mathrm{O}_{2}{ }^{-}$(methanol, DMPO); ${ }^{1} \mathrm{O}_{2}$ (water, 2, 2, 6, 6-tetramethylpiperidine (TEMP)); (b) phenol degradation and (c) $\mathrm{Cr}(\mathrm{VI})$ reduction with different radical scavengers in mixed systems.

3.3. Determination of active species. EPR was used to confirm the active species of phenol oxidation and $\mathrm{Cr}(\mathrm{VI})$ reduction (Figure 4a). Under visible-light irradiation, active oxygen species, including radicals $\cdot \mathrm{OH}$ and $\cdot \mathrm{O}_{2}{ }^{-}$, and non-radical ${ }^{1} \mathrm{O}_{2}$, can all be detected from the $\mathrm{Ag} / \mathrm{AgCl} / \mathrm{MIL}-101(\mathrm{Fe})$ composite. Photocatalytic experiments were carried out in the presence of different sacrificial agents to analyze the main active species responsible for $\mathrm{Cr}(\mathrm{VI})$ reduction and phenol degradation (Figure $4 \mathrm{~b}, \mathrm{c}$ ). Pbenzoquinone (PBQ), sodium oxalate $\left(\mathrm{Na}_{2} \mathrm{C}_{2} \mathrm{O}_{4}\right)$, tert-butanol (TBA), 2, 2, 6, 6tetramethylpiperidine (TEMP), and sodium iodate $\left(\mathrm{NaIO}_{3}\right)$ were used to capture $\cdot \mathrm{O}_{2}{ }^{-}$, holes, $\cdot \mathrm{OH},{ }^{1} \mathrm{O}_{2}$ and electrons in the solution. For the phenol oxidation, the prohibition effect by hole capturer $\mathrm{Na}_{2} \mathrm{C}_{2} \mathrm{O}_{4}, \cdot \mathrm{OH}$ capturer TBA, and $\cdot \mathrm{O}_{2}{ }^{-}$capturer PBQ follows the order of $\mathrm{Na}_{2} \mathrm{C}_{2} \mathrm{O}_{4}>\mathrm{TBA}>\mathrm{PBQ}$ (Figure $4 \mathrm{~b}$ ). Specifically, the former two show comparable prohibition effects and seem far more efficient than PBQ, 
demonstrating $\cdot \mathrm{OH}$ evolved from holes should be the main active species for phenol degradation. Moreover, the significantly decreased activity for phenol in the presence of $\mathrm{NaIO}_{3}$ should be ascribed to the oxidation of $\mathrm{Ag}$ by the hole that remained in the composite, demonstrating the essential role of the surface plasmon resonance (SPR) effect. A similar effect of the capturer agent on the phenol degradation was also observed in the single system (Figure $\mathrm{S} 10$ ). Based on the above results, $\cdot \mathrm{OH}$ radical should be the main active species for phenol degradation.
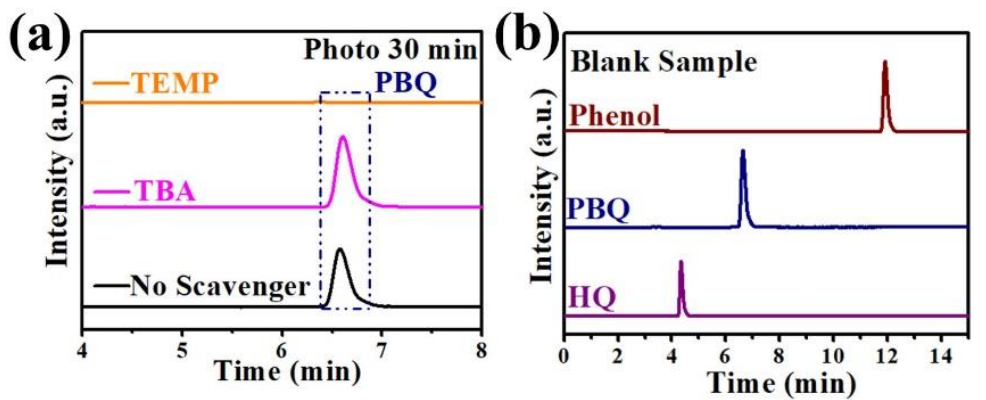

Figure 5. (a) HPLC chromatograms of reaction products of phenol degradation in the $1 \%$ $\mathrm{Ag} / \mathrm{Ag} / \mathrm{MIL}-101(\mathrm{Fe}) / \mathrm{Cr}(\mathrm{VI}) / \mathrm{phenol} /$ light system at $30 \mathrm{~min}$. (PBQ (1 mM), TBA (2 mM), TEMP (5 mM)), (a) reserve time 0-8min, (b) blank phenol, PBQ and HQ.

For the $\mathrm{Cr}(\mathrm{VI})$ reduction (Figure 4c), TEMP most efficiently retards the $\mathrm{Cr}(\mathrm{VI})$ reduction, suggesting ${ }^{1} \mathrm{O}_{2}$ is the key species to induce the reduction. The contribution of $\mathrm{Fe}(\mathrm{II})$ to the $\mathrm{Cr}(\mathrm{VI})$ reduction should be excluded since more $\mathrm{Fe}(\mathrm{II})$ is formed during the first run, and the content keeps stable afterwards. It was reported HQ could be oxidized from phenol by ${ }^{1} \mathrm{O}_{2}$ (Eq. 2). ${ }^{31,34,53}$ It is highly possible that HQ may cause the significantly promoted $\mathrm{Cr}(\mathrm{VI})$ reduction, which is consistent with the lagged $\mathrm{Cr}(\mathrm{VI})$ reduction compared with the phenol degradation. This consumption was supported by the enhanced $\mathrm{Cr}(\mathrm{VI})$ reduction in the presence of $\mathrm{HQ}$ under dark conditions (Figure S11). Moreover, according to the previous report, the reaction between $\mathrm{HQ}$ and $\mathrm{Cr}(\mathrm{VI})$ can successively produce SQ and PBQ (Eq. 3, 4) ${ }^{54}$ The HPLC analysis of the product after 30 min irradiation in the presence of TEMP indicates the disappearance of PBQ signal (Figure 5), which further verifies the above consumption that ${ }^{1} \mathrm{O}_{2}$-induced $\mathrm{HQ}$ is responsible for the $\mathrm{Cr}(\mathrm{VI})$ reduction. The addition of PBQ to the photocatalysis system helps accelerate the $\mathrm{Cr}(\mathrm{VI})$ reduction within the first 15 minutes but decreases the 
overall efficiency. It is assumed that PBQ consumes $\cdot \mathrm{O}_{2}{ }^{-}$and produce $\mathrm{SQ}$, which is also active for the $\mathrm{Cr}(\mathrm{VI})$ reduction $(\mathrm{Eq} .4,5)$; the gradually retarded $\mathrm{Cr}(\mathrm{VI})$ reduction suggests ${ }^{1} \mathrm{O}_{2}$ should be transformed from $\cdot \mathrm{O}_{2}^{-}$since the consumption of $\cdot \mathrm{O}_{2}{ }^{-}$by PBQ is unfavorable to the formation of ${ }^{1} \mathrm{O}_{2}$. The decreased reduction rate of $\mathrm{Cr}(\mathrm{VI})$ in the presence of electron-capturer $\mathrm{NaIO}_{3}$ should be related to the less efficient formation of $\cdot \mathrm{O}_{2}^{-}$, further confirming the evolution of ${ }^{1} \mathrm{O}_{2}$ from $\cdot \mathrm{O}_{2}{ }^{-}$. The slightly decreased reduction rate in the presence of TBA suggests the formation of quinone derivatives should be partly caused by $\cdot \mathrm{OH}$. It was previously reported that $\cdot \mathrm{OH}$, together with $\mathrm{O}_{2}$, could also oxidize phenol to HQ (Equation 6). ${ }^{54}$ However, the presence of $\cdot \mathrm{OH}$ capturer TBA in the mixed reaction system does not cause the disappearance of the PBQ signal in the HPLC chromatogram (Figure 5a), demonstrating HQ should be mainly oxidized from phenol by ${ }^{1} \mathrm{O}_{2}$. The accelerated $\mathrm{Cr}(\mathrm{VI})$ reduction in the presence of $\mathrm{Na}_{2} \mathrm{C}_{2} \mathrm{O}_{4}$ should result from the formation of $\cdot \mathrm{CO}_{2}{ }^{-}$radicals with reducibility to $\mathrm{Cr}(\mathrm{VI}){ }^{55}$

$$
\begin{aligned}
& { }^{1} \mathrm{O}_{2}+\text { Phenol } \rightarrow \mathrm{HQ} \\
& \mathrm{Cr}(\mathrm{VI})+\mathrm{HQ} \leftrightarrows \mathrm{Cr}(\mathrm{III})+\mathrm{SQ} \\
& \mathrm{Cr}(\mathrm{VI})+\mathrm{SQ} \leftrightarrows \mathrm{Cr}(\mathrm{III})+\mathrm{PBQ} \\
& \mathrm{PBQ}+\cdot \mathrm{O}_{2}^{-} \rightarrow \mathrm{SQ} \\
& \cdot \mathrm{OH}+\mathrm{O}_{2}+\text { Phenol } \rightarrow \mathrm{HQ}+\mathrm{HO}_{2}
\end{aligned}
$$
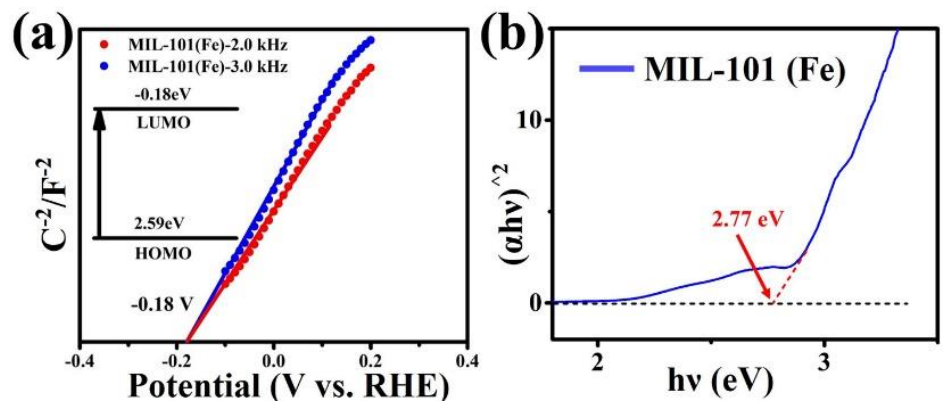

Figure 6. (a) Mott-Schottky plots for MIL-101(Fe) in a $0.1 \mathrm{M} \mathrm{Na}_{2} \mathrm{SO}_{4}$ aqueous solution; (b) bandgap determination for (MIL-101(Fe).

To understand the relation between the carrier transfer in the $\mathrm{Ag} / \mathrm{AgCl} / \mathrm{MIL}-101(\mathrm{Fe})$ composite and the evolution of active oxygen species, the electrochemical characteristics were further studied through Mott-Schottky measurements performed at the frequencies of 2000 and $3000 \mathrm{~Hz}$. The intersection point is independent of the 
frequency and the flat band position determined from the intersection is $-0.18 \mathrm{~V}$ (Figure 6a), which is approximately used as the conduction band minimum (CBM). The bandgap of MIL-101(Fe) is $2.77 \mathrm{~V}$ according to the Tauc plot (Figure 6b), and the calculated valence band maximum (VBM) is $2.59 \mathrm{~V} .{ }^{56-58}$ The CBM and VBM levels of $\mathrm{AgCl}$ are -0.06 and $3.19 \mathrm{~V}$ according to the previous reports, ${ }^{59}$ indicating $\mathrm{AgCl}$ can not be excited by the visible light. According to the improved Ag content during the firstrun photocatalytic process, it is assumed the visible-light-excited MIL-101(Fe) may first transfer electrons to $\mathrm{AgCl}$ in the initial stage of photocatalysis, quickly improving the Ag content and enhancing the SPR effect of the composite. The electrons excited from plasmonic Ag NPs then transfer to the conduction band of $\mathrm{AgCl}$ and form $\cdot \mathrm{O}_{2}{ }^{-}$. Meanwhile, the electrons from MIL-101(Fe) are supposed to transfer to Ag and compensate the hole, stabilizing the electronic state of plasmonic Ag. The hole that remained in MIL-101(Fe) is supposed to result in a higher $\mathrm{Fe}(\mathrm{III})$ after the photocatalytic reaction. However, the contents of Fe(II) and Fe(III) sample keeps stable in the subsequent cyclic reactions. It is thus assumed that the in situ formed Fe(III) should further react with $\cdot \mathrm{O}_{2}{ }^{-}$, simultaneously forming ${ }^{1} \mathrm{O}_{2}$ and reducing $\mathrm{Fe}(\mathrm{III})$ to $\mathrm{Fe}$ (II) (Eq. 7, 8).

$$
\begin{aligned}
& \mathrm{Fe}(\mathrm{II})+\mathrm{h}^{+} \rightarrow \mathrm{Fe}(\mathrm{III}) \\
& \mathrm{Fe}(\mathrm{III})+\cdot \mathrm{O}_{2}^{-} \rightarrow \mathrm{Fe}(\mathrm{II})+{ }^{1} \mathrm{O}_{2}
\end{aligned}
$$

Furthermore, the relation between ${ }^{1} \mathrm{O}_{2}$ and $\mathrm{Cr}(\mathrm{VI})$ reduction was analyzed based on the above assumption. First, according to the LC-MS analysis, both quinone derivatives (HQ, PBQ, SQ) and ring-opening products (fumaric acid, maleic acid, oxalic acid, etc.) can be detected (Table S2, Figure S12). The possible step-by-step degradation process of phenol is shown in Figure S13. Quinone derivatives are commonly observed in the presence of active oxygen species, including $\cdot \mathrm{OH}$ and ${ }^{1} \mathrm{O}_{2}$. Since $\cdot \mathrm{OH}$ radical has a higher oxidation potential, most of the quinone derivatives should be attacked by $\cdot \mathrm{OH}$ and more deeply oxidized to ring-opening products in the initial phase. $\operatorname{The} \mathrm{Cr}(\mathrm{VI})$ reduction was dramatically promoted until over $70 \%$ of phenol was oxidized. Therefore, 
it is assumed that with the consumption of holes to form $\cdot \mathrm{OH}$ in the initial stage, $\cdot \mathrm{O}_{2}{ }^{-}$ should be gradually accumulated and evolved into ${ }^{1} \mathrm{O}_{2}$. More quinone derivatives are then produced, which promote $\mathrm{Cr}(\mathrm{VI})$ reduction in the lagged stage.

The reducibility of quinone derivatives can be enhanced in the strong acidic system. ${ }^{6}$

${ }^{7}$ To more explicitly demonstrate the effect of quinone derivatives on $\mathrm{Cr}(\mathrm{VI})$ reduction, the influence of $\mathrm{pH}$ variation on the $\mathrm{Cr}(\mathrm{VI})$ reduction was further explored during the photocatalysis. Sample 1\% Ag/AgCl/MIL-101(Fe) used here has an isoelectric point of 4.2 (Figure S14). The original $\mathrm{pH}$ value of the phenol-Cr(VI) mixture is 3.8 and tuned to 6.0 to exclude the electrostatic adsorption. The $\mathrm{pH}$ decreased to ca. 4.6 in the first 30 min and finally reached 4.2 (Figure S15a), which verifies the photo-induced electron is not the main active species for $\mathrm{Cr}(\mathrm{VI})$ reduction. Photo-induced electrons should cause the slow $\mathrm{Cr}(\mathrm{VI})$ reduction in the initial stage through the random collision between photocatalyst and $\mathrm{Cr}(\mathrm{VI})$. The effect of decreased $\mathrm{pH}$ on the reduction ability of quinone derivatives was explored over the $\mathrm{HQ}-\mathrm{Cr}(\mathrm{VI})$ mixture. The original $\mathrm{pH}$ value of HQ-Cr(VI) mixture was ca. 4.2 and tuned to 6.0 (Figure $\mathrm{S} 15 \mathrm{~b}$ ). The $\mathrm{Cr}(\mathrm{VI})$ reduction efficiency was not obviously influenced by the initial $\mathrm{pH}$ value of the mixture, demonstrating the decreased $\mathrm{pH}$ in the phenol-Cr(VI) mixture under continuous irradiation is not responsible for the enhanced $\mathrm{Cr}(\mathrm{VI})$ reduction.

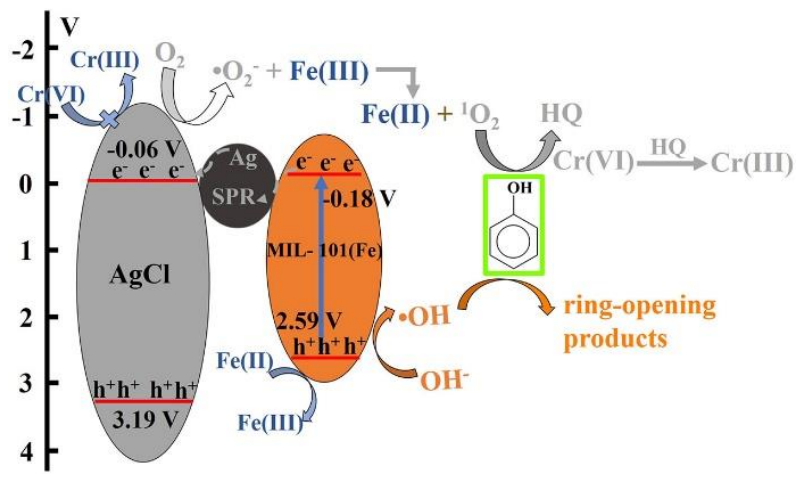

Scheme 2. Proposed photocatalytic mechanism.

3.4. Photocatalytic mechanism. Based on the above results, we proposed the photocatalytic mechanism of $\mathrm{Ag} / \mathrm{AgCl} / \mathrm{MIL}-101(\mathrm{Fe})$ for the combined treatment of phenol and $\mathrm{Cr}(\mathrm{VI})$ (Scheme 2). Under the irradiation of visible light, both Ag and MIL- 
101(Fe) can be excited. The hot electrons can be produced from Ag benefitting from the SPR effect and charged to $\mathrm{AgCl}$, which lead to the formation of $\cdot \mathrm{O}_{2}{ }^{-}$. The photoinduced electrons can not efficiently reduce anion $\mathrm{Cr}(\mathrm{VI})$ due to the poor surface adsorption. Meanwhile, the electrons excited from MIL-101(Fe) can be charged to Ag and keeps it active under the visible light irradiation. The holes remained in MIL101(Fe) oxidize $\mathrm{Fe}(\mathrm{II})$ to $\mathrm{Fe}(\mathrm{III})$ and surface hydroxyls to $\cdot \mathrm{OH}$. $\mathrm{Fe}(\mathrm{III})$ species further induces the formation of ${ }^{1} \mathrm{O}_{2}$ from $\cdot \mathrm{O}_{2}{ }^{-}$. Both $\cdot \mathrm{OH}$ and ${ }^{1} \mathrm{O}_{2}$ oxidize phenol to quinone derivatives, and aggressive $\cdot \mathrm{OH}$ radicals further cause the ring-opening and mineralization of quinone derivatives, which are more consumed in the initial phase. Quinone derivatives oxidize from ${ }^{1} \mathrm{O}_{2}$ are then accumulated and promote the $\mathrm{Cr}(\mathrm{VI})$ reduction in the lagged phase.

\section{CONCLUSION.}

In summary, ternary heterojunction $\mathrm{Ag} / \mathrm{AgCl} / \mathrm{MIL}-101(\mathrm{Fe})$ was formed by simply mixing Ag with MIL-101(Fe). This composite showed a cooperative effect for phenol degradation and $\mathrm{Cr}(\mathrm{VI})$ reduction. $\cdot \mathrm{OH}$ is responsible for the phenol degradation and the quinone derived from the reaction between phenol and ${ }^{1} \mathrm{O}_{2}$ significantly promotes $\mathrm{Cr}(\mathrm{VI})$ reduction. This study discriminates the effect of quinone derivatives on the $\mathrm{Cr}(\mathrm{VI})$ reduction from that of photo-induced electrons during the photocatalytic treatment of phenol-Cr(VI) mixture. It provides a joint treatment strategy for the phenol-Cr(VI) mixture that is not limited by the prerequisite for surface adsorption of metal ions on the catalyst surface. Moreover, the application of MOFs in water pollutant treatment has been commonly restricted by the poor carrier separation efficiency and instability. Here, the cooperation between SPR-Ag, conjugated $\mathrm{AgCl}$ and $\mathrm{MOF}-101(\mathrm{Fe})$ provides an efficient way for achieving excellent carrier separation and improving the photo-stability.

\section{ASSOCIATED CONTENT}

\section{Supporting Information.}


The Supporting Information is available free of charge at DOI: XXXXX.

SEM, HRTEM, The comparison of kinetic constants, UV-vis DRS, Photocurrent and EIS spectral analyses, $\mathrm{N}_{2}$ adsorption-desorption isotherm and corresponding pore size, single Cr(VI) reduction and phenol degradation, XPS spectral analysis, effect of HQ and PBQ addition on the Cr(VI) reduction, possible intermediates in phenol degradation, MS spectra, degradation process of phenol, the isoelectric point, the change of $\mathrm{pH}$ value, apparent quantum efficiency of $\mathrm{Cr}$ (VI) (PDF)

\section{AUTHOR INFORMATION}

\section{Corresponding Author}

Tel.: +86 21 64252062; Fax: +86 21 64252062. E-mail: wlz@ecust.edu.cn;

\section{Author Contributions}

Jianqiu Gong and Weiwei Zhang contributed equally to this work. The manuscript was written with contributions from all authors. All authors have approved the final version of the manuscript.

\section{Notes}

The authors declare no competing financial interest.

\section{ACKNOWLEDGMENT.}

This work was supported by the Science and Technology Commission of Shanghai Municipality (18520710200, 20DZ2250400), the National Natural Science Foundation of China (21972040, 21673073), Shanghai Pujiang Program (18PJD012), Project supported by Shanghai Municipal Science and Technology Major Project (No.2018SHZDZX03) and the Program of Introducing Talents of Discipline to Universities (No. B20031, B16017).

\section{REFERENCES}


(1) Diao, Z. H.; Xu, X. R.; Jiang, D.; Kong, L. J.; Sun, Y. X.; Hu, Y. X.; Hao, Q. W.; Chen, H. Bentonite-supported nanoscale zero-valent iron/persulfate system for the simultaneous removal of $\mathrm{Cr}(\mathrm{VI})$ and phenol from aqueous solutions. Chem. Eng. J. 2016, 302, 213-222.

(2) Gładysz-Płaska, A.; Majdan, M.; Pikus, S.; Sternik, D. Simultaneous adsorption of chromium(VI) and phenol on natural red clay modified by HDTMA. Chem. Eng. J. 2012, 179, 140-150.

(3) Lu, D.; Chai, W.; Yang, M.; Fang, P.; Wu, W.; Zhao, B.; Xiong, R.; Wang, H. Visible light induced photocatalytic removal of $\mathrm{Cr}(\mathrm{VI})$ over $\mathrm{TiO}_{2}$-based nanosheets loaded with surface-enriched $\mathrm{CoO}_{\mathrm{x}}$ nanoparticles and its synergism with phenol oxidation. Appl. Catal. B-Environ. 2016, 190, 44-65.

(4) Aksu, Z.; Gönen, F. Binary biosorption of phenol and chromium(VI) onto immobilized activated sludge in a packed bed: Prediction of kinetic parameters and breakthrough curves. Sep. Purif. Technol. 2006, 49, 205-216.

(5) Chirwa, E. N.; Wang, Y. T. Simultaneous chromium(VI) reduction and phenol degradation in an anaerobic consortium of bacteria. Water Res. 2000, 34, 2376-2384.

(6) Elovitz, M. S.; Fish, W. Redox Interactions of Cr(VI) and Substituted Phenols: Kinetic Investigation. Environ. Sci. Technol. 1994, 28, 2161-2169.

(7) Elovitz, M. S.; Fish, W. Redox interactions of Cr (VI) and substituted phenols: products and mechanism. Environ. Sci. Technol. 1995, 29, 1933-1943.

(8) Dozzi, M. V.; Saccomanni, A.; Selli, E. Cr(VI) photocatalytic reduction: Effects of simultaneous organics oxidation and of gold nanoparticles photodeposition on $\mathrm{TiO}_{2}$. J. Hazard. Mater. 2012, 211, 188-195.

(9) Lee, S. M.; Lee, T. W.; Choi, B. J.; Yang, J. K. Treatment of Cr(VI) and Phenol by Illuminated $\mathrm{TiO}_{2}$. J. Environ. Sci. Heal. A 2003, 38, 2219-2228.

(10) Wang, L.; Wang, N.; Zhu, L.; Yu, H.; Tang, H. Photocatalytic reduction of $\mathrm{Cr}(\mathrm{VI})$ over different $\mathrm{TiO}_{2}$ photocatalysts and the effects of dissolved organic species. J. Hazard. Mater. 2008, 152, 93-99.

(11) Liu, F.; Yu, J.; Tu, G.; Qu, L.; Xiao, J.; Liu, Y.; Wang, L.; Lei, J.; Zhang, J. Carbon nitride coupled Ti-SBA15 catalyst for visible-light-driven photocatalytic reduction of $\mathrm{Cr}$ (VI) and the synergistic oxidation of phenol. Appl. Catal. B-Environ. 2017, 201, 1-11.

(12) Liang, H.; Li, T.; Zhang, J.; Zhou, D.; Hu, C.; An, X.; Liu, R.; Liu, H. 3-D hierarchical Ag/ZnO@CF for synergistically removing phenol and $\mathrm{Cr}(\mathrm{VI})$ :

Heterogeneous vs. homogeneous photocatalysis. J. Colloid Interf. Sci. 2020, 558, 8594.

(13) Fu, H.; Lu, G.; Li, S. Adsorption and photo-induced reduction of Cr (VI) ion in $\mathrm{Cr}$ (VI)-4CP (4-chlorophenol) aqueous system in the presence of $\mathrm{TiO}_{2}$ as photocatalyst. J. Photoch. Photobio. A 1998, 114, 81-88.

(14) Sun, K.; Jia, F.; Yang, B.; Lin, C.; Li, X.; Song, S. Synergistic effect in the reduction of $\mathrm{Cr}(\mathrm{VI})$ with $\mathrm{Ag}-\mathrm{MoS}_{2}$ as photocatalyst. Appl. Mater Today 2020, 18, 100453. 
(15) Borthakur, P.; Boruah, P. K.; Das, M. R.; Artemkina, S. B.; Poltarak, P. A.;

Fedorov, V. E. Metal free $\mathrm{MoS}_{2} 2 \mathrm{D}$ sheets as a peroxidase enzyme and visible-lightinduced photocatalyst towards detection and reduction of $\mathrm{Cr}(\mathrm{VI})$ ions. New J. Chem. 2018, 42, 16919-16929.

(16) Hu, C.; Huang, Y. C.; Chang, A. L.; Nomura, M. Amine functionalized ZIF-8 as a visible-light-driven photocatalyst for $\mathrm{Cr}(\mathrm{VI})$ reduction. J. Colloid Interf. Sci. 2019, 553, 372-381.

(17) Sahoo, D. P.; Patnaik, S.; Rath, D.; Parida, K. M. Synergistic effects of plasmon induced $\mathrm{Ag} @ \mathrm{Ag}_{3} \mathrm{VO}_{4} / \mathrm{ZnCr} \mathrm{LDH}$ ternary heterostructures towards visible light responsive $\mathrm{O}_{2}$ evolution and phenol oxidation reactions. Inorg. Chem. Front. 2018, 5, 879.

(18) Sahoo, D. P.; Patnaik, S.; Parida, K. M. Construction of a Z-Scheme Dictated $\mathrm{WO}_{3}-\mathrm{X} / \mathrm{Ag} / \mathrm{ZnCr} \mathrm{LDH}$ Synergistically Visible Light-Induced Photocatalyst towards Tetracycline Degradation and $\mathrm{H}_{2}$ Evolution. ACS Omega 2019, 4, 14724-14741.

(19) Subudhi, S.; Swain, G.; Tripathy, S. P.; Parida, K. M. UiO-66-NH2 MetalOrganic Frameworks with Embedded $\mathrm{MoS}_{2}$ Nanoflakes for Visible-Light-Mediated $\mathrm{H}_{2}$ and $\mathrm{O}_{2}$ Evolution. Inorg. Chem. 2020, 59, 9824-9837.

(20) Subudhi, S.; Mansingh, S.; Swain, G.; Behera, A.; Rath, D.; Parida, K. M. HPWAnchored UiO-66 Metal-Organic Framework: A Promising Photocatalyst Effective toward Tetracycline Hydrochloride Degradation and $\mathrm{H}_{2}$ Evolution via Z-Scheme Charge Dynamics. Inorg. Chem. 2019, 58, 4921-4934.

(21) Subudhi, S.; Mansingh, S.; Tripathy, S. P.; Mohanty, A.; Mohapatra, P.; Rathd, D.; Parida, K. M. The fabrication of Au/Pd plasmonic alloys on UiO66- $\mathrm{NH}_{2}$ : an efficient visible light-induced photocatalyst towards the Suzuki Miyaura coupling reaction under ambient conditions. Catal. Sci. Technol. 2019, 9, 6585.

(22) Patnaik, S.; Swain, G.; Parida K. M. Highly efficient charge transfer through a double $\mathrm{Z}$-scheme mechanism by a $\mathrm{Cu}$-promoted $\mathrm{MoO}_{3} / \mathrm{g}-\mathrm{C}_{3} \mathrm{~N}_{4}$ hybrid nanocomposite with superior electrochemical and photocatalytic performance. Nanoscale 2018, 10, 5950.

(23) Gao, Z.; Yang, H.; Fu, X.; Jin, Q.; Wu, Q.; Kang, L.; Wu, J. Efficient photoreduction of $\mathrm{Cr}(\mathrm{VI})$ on $\mathrm{TiO}_{2} /$ functionalized activated carbon $\left(\mathrm{TiO}_{2} / \mathrm{AC}-\mathrm{AEMP}\right)$ : improved adsorption of $\mathrm{Cr}(\mathrm{VI})$ and induced transfer of electrons. Environ. Sci. Pollut. R. 2020, 27, 17446-17457.

(24) Li, X.; Chen, D.; Li, N.; Xu, Q.; Li, H.; He, J.; Lu, J. Efficient reduction of $\mathrm{Cr}(\mathrm{VI})$ by a $\mathrm{BMO} / \mathrm{Bi}_{2} \mathrm{~S}_{3}$ heterojunction via synergistic adsorption and photocatalysis under visible light. J. Hazard. Mater. 2020, 400, 123243.

(25) Gao, Y.; Chen, C.; Tan, X.; Xu, H.; Zhu, K. Polyaniline-modified 3D-flower-like molybdenum disulfide composite for efficient adsorption/photocatalytic reduction of Cr(VI). J. Colloid Interf. Sci. 2016, 476, 62-70.

(26) Yang, Y.; Li, J.; Yan, T.; Zhu, R.; Yan, L.; Pei, Z. Adsorption and photocatalytic reduction of aqueous $\mathrm{Cr}(\mathrm{VI})$ by $\mathrm{Fe}_{3} \mathrm{O}_{4}-\mathrm{ZnAl}$-layered double hydroxide/ $/ \mathrm{TiO}_{2}$ composites. J. Colloid Interf. Sci. 2020, 562, 493-501. 
(27) He, X.; Chi, H.; He, M.; Zhang, B.; Zhang, J.; Wang, D.; Ma, J. Efficient removal of halogenated phenols by vacuum-UV system through combined photolysis and $\mathrm{OH}$ oxidation: Efficiency, mechanism and economic analysis. J. Hazard. Mater. 2021, 403, 123286.

(28) Xu, C.; Wang, L. Atmospheric Oxidation Mechanism of Phenol Initiated by $\mathrm{OH}$ Radical. J. Phys. Chem. A 2013, 117, 2358-2364.

(29) Yazdanbakhsh, A.; Aliyari, A.; Sheikhmohammadi, A.; Aghayani, E. Application of the enhanced sono-photo-Fenton-like process in the presence of persulfate for the simultaneous removal of chromium and phenol from the aqueous solution. J. Water Process Eng. 2020, 34, 101080.

(30) Xu, T.; Lu, W.; Wu, X. F.; Chen, W.; Solar-driven conversion of arylboronic acids to phenols using metal-free heterogeneous photocatalysts. J. Catal. 2019, 378, 63-67.

(31) Piwowar, K.; Blacha-Grzechnik, A.; Bernas, P.; Zak, J. Phenol degradation in heterogeneous system generating singlet oxygen employing light activated electropolymerized phenothiazines. Appl. Surf. Sci. 2015, 359, 426-431.

(32) Zhou, Y.; Jiang, J.; Gao, Y.; Pang, S. Y.; Yang, Y.; Ma, J.; Gu, J.; Li, J.; Wang, Z.; Wang, L. H.; Yuan, L. P.; Yang, Y. Activation of peroxymonosulfate by phenols: Important role of quinone intermediates and involvement of singlet oxygen. Water Res. 2017, 125, 209-218.

(33) Tian, X.; Gao, P.; Nie, Y.; Yang, C.; Zhou, Z.; Li, Y.; Wang, Y. A novel singlet oxygen involved peroxymonosulfate activation mechanism for degradation of ofloxacin and phenol in water. Chem. Commun. 2017, 53, 6589-6592.

(34) Feng, J.; Li, S.; Sheng, Y.; Xiong, Y.; Lan, S.; Tian, S.; Kong, L.; Fan, C. Remarkable improvement of cycling Fenton process for catalytic degradation of phenol: Tuning of triggering effect. Appl. Catal. A-Gen. 2017, 542, 21-27.

(35) Lv, K.; Guo, X.; Wu, X.; Li, Q.; Ho, W.; Li, M.; Ye, H.; Du, D. Photocatalytic selective oxidation of phenol to produce dihydroxybenzenes in $\mathrm{TiO}_{2} / \mathrm{UV}$ system: Hydroxyl radical versus hole. Appl. Catal. B-Environ. 2016, 199, 405-411.

(36) Minero, C.; Mariella, G.; Maurino, V.; Pelizzetti, E. Photocatalytic transformation of organic compounds in the presence of inorganic anions. 1. Hydroxyl-mediated and direct electron-transfer reactions of phenol on a titanium dioxide -fluoride system. Langmuir 2000, 16, 2632-2641.

(37) Chen, C.; Zhao, W.; Lei, P.; Zhao, J.; Serpone, N. Photosensitized Degradation of Dyes in Polyoxometalate Solutions Versus $\mathrm{TiO}_{2}$ Dispersions under Visible-Light Irradiation: Mechanistic Implications. Chem-Eur J. 2004, 10, 1956-1965.

(38) Yi, Q.; Ji, J.; Shen, B.; Dong, C.; Liu, J.; Zhang, J.; Xing, M. Singlet Oxygen Triggered by Superoxide Radicals in a Molybdenum Cocatalytic Fenton Reaction with Enhanced Redox Activity in the Environment. Environ. Sci. Technol. 2019, 53, 9725-9733.

(39) Jedsukontorn, T.; Meeyoo, V.; Saito, N.; Hunsom, M. Effect of electron acceptors $\mathrm{H}_{2} \mathrm{O}_{2}$ and $\mathrm{O}_{2}$ on the generated reactive oxygen species ${ }^{1} \mathrm{O}_{2}$ and $\mathrm{OH}$ in $\mathrm{TiO}_{2}-$ catalyzed photocatalytic oxidation of glycerol. Chinese J. Catal. 2016, 37, 1975-1981. 
(40) Alvaro, M.; Carbonell, E.; Ferrer, B.; Llabrési Xamena, F. X.; Garcia, H.

Semiconductor Behavior of a Metal-Organic Framework (MOF). Chem-Eur. J. 2007, 13, 5106-5112.

(41) Xamena, F. X. L. I.; Corma, A.; Garcia, H. Applications for Metal-Organic

Frameworks (MOFs) as Quantum Dot Semiconductors. J. Phys. Chem. C 2007, 111, 80-85.

(42) Pu, S.; Xu, L.; Sun, L.; Du, H. Tuning the optical properties of the zirconiumUiO-66 metal-organic framework for photocatalytic degradation of methyl orange. Inorg. Chem. Commun. 2015, 52, 50-52.

(43) Jing, H. P.; Wang, C. C.; Zhang, Y. W.; Wang, P.; Li, R. Photocatalytic degradation of methylene blue in ZIF-8. RSC Adv. 2014, 4, 54454-54462.

(44) Sha, Z.; Chan, H. S. O.; Wu, J. $\mathrm{Ag}_{2} \mathrm{CO}_{3} / \mathrm{UiO}-66(\mathrm{Zr})$ composite with enhanced visible-light promoted photocatalytic activity for dye degradation. J. Hazard. Mater.

2015, 299, 132-140.

(45) Du, D. Y.; Qin, J. S.; Li, S. L.; Su, Z. M.; Lan, Y. Q. J. C. S. R. Recent advances in porous polyoxometalate-based metal-organic framework materials. Chem. Soc.

Rev. 2014, 43, 4615-4632.

(46) Xuan, W.; Zhu, C.; Liu, Y.; Cui, Y. J. C. S. R. Mesoporous metal-organic framework materials. Chem. Soc. Rev. 2012, 41, 1677-1695.

(47) Salunkhe, R. R.; Kaneti, Y. V.; Yamauchi, Y. J. A. N. Metal-organic frameworkderived nanoporous metal oxides toward supercapacitor applications: progress and prospects. ACS Nano. 2017, 11, 5293-5308.

(48) Toyao, T.; Saito, M.; Dohshi, S.; Mochizuki, K.; Iwata, M.; Higashimura, H.; Horiuchi, Y.; Matsuoka, M. J. C. C. Development of a Ru complex-incorporated MOF photocatalyst for hydrogen production under visible-light irradiation. Chem. Commun. 2014, 50, 6779-6781.

(49) Zhao, M.; Yuan, K.; Wang, Y.; Li, G.; Guo, J.; Gu, L.; Hu, W.; Zhao, H.; Tang, Z. Metal-organic frameworks as selectivity regulators for hydrogenation reactions. Nature 2016, 539, 76-80.

(50) Weckhuysen, B. M.; Wachs, I. E.; Schoonheydt, R. A. Surface Chemistry and Spectroscopy of Chromium in Inorganic Oxides. Chem. Rev. 1996, 96, 3327-3350.

(51) Salunkhe, R. R.; Kaneti, Y. V.; Yamauchi, Y. Metal-organic framework-derived nanoporous metal oxides toward supercapacitor applications: progress and prospects. ACS Nano. 2017, 11, 5293-5308.

(52) Bordiga, S.; Lamberti, C.; Ricchiardi, G.; Regli, L.; Bonino, F.; Damin, A.; Lillerud, K.-P.; Bjorgen, M.; Zecchina, A. Electronic and vibrational properties of a MOF-5 metal-organic framework: $\mathrm{ZnO}$ quantum dot behaviour. Chem. Commun. 2004, 20, 2300-2301.

(53) Han, S. K.; Bilski, P.; Karriker, B.; Sik, R. H.; Chignell, C. F. Oxidation of flame retardant tetrabromobisphenol A by singlet oxygen. Environ. Sci. Technol. 2008, 42, 166-172. 
(54) Chen, R.; Pignatello, J. J. Role of quinone intermediates as electron shuttles in Fenton and photoassisted Fenton oxidations of aromatic compounds. Environ. Sci. Technol. 1997, 31, 2399-2406.

(55) Ren, H.; Hou, Z.; Han, X.; Zhou, R. Highly reductive radical $\mathrm{CO}_{2}$-deriving from a system with $\mathrm{SO}_{4}{ }^{-}$and formate anion: Implication for reduction of $\mathrm{Cr}(\mathrm{VI})$ from wastewater. Chem. Eng. J. 2017, 309, 638-645.

(56) Lu Z.; Zhou G.; Song M.; Liu X.; Tang H.; Dong H.; Huo P.; Yan F.; Du P.; Xing G. Development of magnetic imprinted PEDOT/CdS heterojunction photocatalytic nanoreactors: 3-Dimensional specific recognition for selectively photocatalyzing danofloxacin mesylate. Appl. Catal. B-Environ. 2020, 268, 118433 (57) Lu Z.; Zhou G.; Song M.; Wang D.; Huo P.; Fan W.; Dong H.; Tang H.; F. Yan; Xing G. Magnetic functional heterojunction reactors with 3D specific recognition for selective photocatalysis and synergistic photodegradation in binary antibiotic solutions. J. Mater. Chem. A 2019, 7, 13986-14000

(58) He F.; Lua Z.; Song M.; Liu X.; Tang H.; Huo P.; Fan W.; Dong H.; Wu X.; Han $\mathrm{S}$. Selective reduction of $\mathrm{Cu}^{2+}$ with simultaneous degradation of tetracycline by the dual channels ion imprinted POPD-CoFe $\mathrm{O}_{4}$ heterojunction photocatalyst. Chem.

Eng. J. 2019, 360, 750-761

(59) Li, X.; Wu, D.; Luo, Q.; Yin, R.; An, J.; Liu, S.; Wang, D. Fabrication of CPAN/Ag/AgCl composites and their efficient visible-light photocatalytic activity. $J$. Alloy Compd. 2017, 702, 585-593.

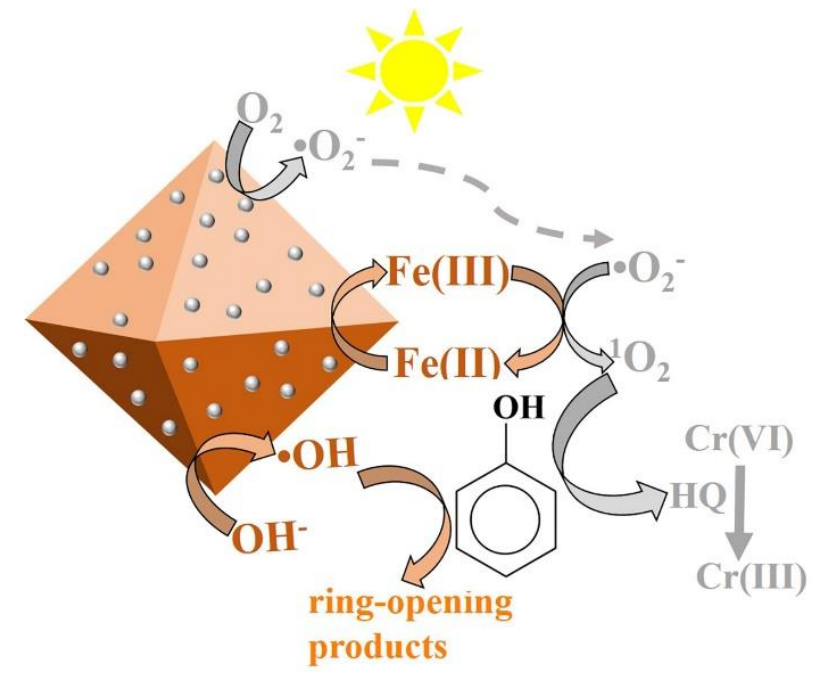

The TOC graph 